\title{
BROMÉLIAS E BEIJA-FLORES: UM MODELO OBSERVACIONAL PARA TESTAR HIPÓTESES SOBRE CORRELAÇÕES E ADAPTAÇÕES MORFOLÓGICAS RECIIPROCAS ${ }^{1}$
}

\author{
Liana Carneiro Capucho ${ }^{2}$, Suely Dalcolmo ${ }^{2}$, \\ Tiago de Holanda Formigoni ${ }^{2}$ \& Ary Gomes da Silva ${ }^{3}$
}

\section{Resumo}

(Bromélias e beija-flores: um modelo observacional para testar hipóteses sobre correlações e adaptações morfológicas recíprocas) Muitas angiospermas dependem da ação de animais para sua polinização. Embora a maioria das interações entre plantas e polinizadores não aparentem ser tão peculiares,de certa forma, parecem envolver algum grau de adaptação mútua de flor e animal. A morfologia floral é um dos mais importantes aspectos de interações planta-polinizador, pois determina a acessibilidade do polinizador ao néctar e a eficiência da deposição do pólen no corpo do polinizador e da aquisição do pólen pelo estigma. O presente trabalho pretende propor e validar uma metodologia que permita testar hipóteses quanto à existência de correlação morfológica entre flores e polinizadores. Uma abordagem de análise de série temporal foi proposta como medida de esforço observacional e a morfometria de comprimento e curvatura de corolas de bromélias e bicos de beija-flores foram utilizados como descritores para um teste de ajustamento, realizado por regressão logística. Em pequena escala, envolvendo quatro espécies de bromélias e sete de beija-flores, resultados levaram à rejeição da hipótese da existência de restrições morfológicas exercidas pelas bromélias no sentido de selecionar beija-flores pelo comprimento ou pela curvatura de seus bicos.

Palavras-chave: polinização, angiospermas, vertebrados, interações animal-planta; regressão logística.

\section{Abstract}

(Bromeliads and hummingbirds: an observational model for hypothesis test on morphological correlation and reciprocal adaptation) Many angiosperms depend on animals for their pollination. Although most of the interactions between plants and pollinators do not seem to be so peculiar, everything seems to involve some degree of mutual adaptation between flowers and animals. Floral morphology is one of the most important aspects of plant-pollinator interactions, because it drives the floral resource accessibility by pollinators. This paper aims to propose and validate a methodology to test hypothesis on morphological correlation between flowers and their pollinators. A temporal series approach was made as an estimation of observational effort. The morphometry of cord and curvature of flower tubes and hummingbird bills were used as descriptors for an adjustment test made by logistic regression. In this modeling scale, with four bromeliads and seven hummingbird species, we rejected the hypothesis of the existence of morphological restriction imposed by bromeliads on the hummingbird selection, by means of its bill length or curvature.

Key words: pollination, angiosperms, vertebrates, animal-plant interaction, logistic regression.

\section{INTRODUÇÃo}

Cerca de $80 \%$ das espécies de angiospermas dependem da ação de animais para a polinização (Bawa et al. 1985). Vários insetos e alguns vertebrados contam com as flores como fonte de recursos, para alimentar ou proteger a si e a sua prole (Feinsinger 1983). Embora a maioria das interações de plantas e polinizadores não aparentem ser tão peculiares, de certa forma, essas interações parecem envolver algum grau de adaptação mútua de flores e visitantes florais (Faegri \& van der Pijl 1979; Fenster et al. 2004).
Numerosas situações demonstram que, apesar de ser uma relação mutualista, a polinização não é uma interação exatamente simétrica quanto à dependência dos organismos envolvidos (Waser et al. 1996). Na verdade, a relação entre polinizadores e flores tem se mostrado bastante flexível em comunidades tropicais, variando circunstancialmente ao longo do tempo evolutivo e do espaço biogeográfico (Roubik 1992). Apesar disto, os serviços de polinização aparecem entre as citações mais freqüentes e ilustrativas de coevolução nas interações de plantas e animais (Herrera 1996).

Artigo recebido em 01/2006. Aceito para publicação em 05/2006.

${ }^{1}$ Trabalho de Conclusão de Curso apresentado à Coordenação do Curso de Ciências Biológicas - ESFA.

${ }^{2}$ Acadêmicos do Curso de Ciências Biológicas - ESFA. Rua Bernardino Monteiro, 700, Bairro Dois Pinheiros, 29650000, Santa Teresa, ES, Brasil. lianacapucho@yahoo.com.br, suelydalcolmo@yahoo.com.br, tiagoholanda@yahoo.com.br. ${ }^{3}$ Orientador, Professor do Curso de Ciências Biológicas - ESFA. Rua Bernardino Monteiro, 700, Bairro Dois Pinheiros, 29650-000, Santa Teresa, ES, Brasil. arygomes@esfa.edu.br. 
Desta idéia deriva o conceito das síndromes de polinização como um conjunto de atributos florais, entre eles os atrativos e os recursos disponíveis, que refletem a especialização entre flores e alguns grupos de visitantes, organizados no nível taxonômico de ordem ou níveis superiores (Faegri \& van der Pijl 1979).

A morfologia floral é um dos importantes aspectos na delimitação das síndromes de polinização, uma vez que pode restringir ou orientar a acessibilidade do visitante aos recursos florais. Desta maneira, muitas vezes atua determinando a forma de deposição do pólen em seu corpo, transformando-o em polinizador com variado grau de eficiência na deposição de pólen no estigma floral (Sakai et al. 1998). Contudo, a variação no local de deposição do pólen no corpo do polinizador pode, por exemplo, promover a coexistência de espécies de plantas que compartilham os mesmos polinizadores, sem que haja entre elas o estabelecimento de relações competitivas (Proctor et al. 1996). Desse modo, considera-se que as plantas que apresentam características particulares em seu sistema de polinização refletem, em longo prazo, a ação da seleção natural por determinados grupos de polinizadores, ou polinizadores que são equivalentes em seu tamanho e comportamento (Waser 1983; Waser et al. 1996).

Diante disso, o presente trabalho pretende propor e validar uma metodologia que permita testar hipóteses quanto à existência de correlação morfológica entre flores e polinizadores. Para isto, pretende delimitar o cenário biológico da polinização de espécies de bromélias por beija-flores, tomado como modelo de estudo para avaliar o grau de reciprocidade de adaptações entre flores e polinizadores.

\section{Material e Métodos}

\section{Cenário biológico do modelo de estudo}

A caracterização do cenário biológico das relações das espécies de bromélias e beijaflores, para validação e teste da metodologia proposta, consistiu em estimar o esforço amostral para levantar a diversidade local de beija-flores visitantes de bromélias, tomando como referência um trabalho realizado na mesma área por Varassin \& Sazima (2000). Tanto para as flores de bromélias como beijaflores, foram levantadas as informações morfológicas mínimas que permitissem dimensionar a escala métrica destas interações, os padrões visuais e de inserção das espécies em questão no ambiente de estudo.

\subsection{Esforço observacional}

O trabalho de campo foi realizado em excursões semanais entre agosto e outubro de 2005, em duas áreas da Estação Biológica de Santa Lúcia-EBSL, município de Santa Teresa,

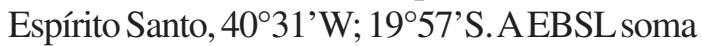
um total de aproximadamente 1,6 hectares cobertos por floresta ombrófila densa montana.

O esforço observacional para estimar a riqueza de espécies de beija-flores visitantes das flores em estudo foi avaliado pela relação existente entre o acúmulo de horas de observação em campo e uma modificação do índice de riqueza de espécies de Whittaker (1975), proposto para comunidades vegetais. O objetivo foi estimar a quantidade de horas de observação necessárias para a inclusão de uma nova espécie entre as já registradas.

Considerando que o avistamento de animais representa uma das formas de levantamento demográfico quando não são aplicadas técnicas de captura (Krebs 1999), no índice de riqueza de espécies aqui proposto houve a substituição do número acumulado de indivíduos amostrados pelo número acumulado de avistamentos dos beija-flores visitantes das flores, conforme equação:

$$
I r=\frac{N s p}{\ln (N o b s)} \text { onde }
$$

Ir = Índice de Riqueza;

Nsp = Número de espécies;

Nobs = Número acumulado de avistamentos de beija-flores

Desta maneira, pretendeu-se estimar a quantidade de horas de observação necessárias para a inclusão de uma nova espécie de beijaflor entre os visitantes já relacionados. 


\subsection{Morfologia floral}

Foram observadas as características vegetativas e florais das espécies de bromélias, tais como: hábito; cor das flores e odor perceptível. Para que se constatasse presença ou ausência de odor nas flores observadas, as mesmas foram colocadas em um frasco fechado por dez minutos. Depois deste período, o frasco foi aberto para que através do olfato se percebesse essa característica da flor.

Uma flor foi coletada em cinco indivíduos de cada espécie e foram conservadas em álcool $70^{\circ} \mathrm{GL}$ e glicerinado em $20 \%$. Nelas foram medidos, em laboratório e com a utilização de paquímetro com precisão de $0,1 \mathrm{~mm}$, o comprimento reto (corda) e a curvatura (arco) do tubo da corola e a altura das estruturas reprodutivas, bem como sua posição em relação à fauce floral.

\subsection{Visitantes florais}

Em campo, as observações dos visitantes florais foram feitas com auxílio de binóculos. Em laboratório, foram medidos, em exemplares taxidermizados com a utilização de paquímetro com precisão de $0,1 \mathrm{~mm}$, o comprimento reto (corda) e a curvatura (arco) dos bicos das espécies de beija-flores que, em campo, foram observadas visitando cada espécie. Os exemplares utilizados fazem parte da coleção científica do Setor de Zoologia do Museu de Biologia Prof. Mello Leitão.

Observações das táticas de forrageamento, ou seja, se as visitas eram legítimas ou não e observação de qual parte do animal toca no estigma e anteras (bico, asa, peito e/ou pescoço, queixo, testa, cabeça) também foram feitas. As observações ocorreram durante todo o dia, sem intervalos (5:30 às 17:00h) ou, em algumas ocasiões, em turnos de observações de quatro horas distribuídos em manhãs e tardes alternadas de diferentes dias.

\section{Correlações morfológicas de flores e bicos de beija-flores}

Com base nas medidas de corda e arco de curvatura da corola e do bico dos beija flores, foi calculado um índice de curvatura (IC) segundo a fórmula:

$$
I C=\frac{\operatorname{Arco}(\mathrm{mm})}{\operatorname{Corda}(\mathrm{mm})}
$$

Índice de curvatura igual a 1,0 indica estrutura reta, enquanto que valores maiores que 1,0 indicam estruturas curvas.

A aderência entre comprimento e curvatura de corolas de bromélias e bicos de beija-flore foi testada por regressão logística ordinal (Hosmer \& Lemeshow 1989). A análise de regressão logística e a determinação de seus respectivos parâmetros diagnósticos foram realizadas no programa estatístico MINITAB, versão 13,0.

\section{Resultados}

\section{O Esforço observacional}

Entre os visitantes, Ramphodon naevius e Glaucis hirsuta foram os mais freqüentes, totalizando $74,9 \%$ dos 235 avistamentos registrados nas 40 horas de observação (Tab. 1).

Tabela 1 - Número total e os respectivos percentuais de avistamentos das espécies de beija-flores visitantes das bromélias observadas na Estação Biológica de Santa Lúcia, Santa Teresa, Espírito Santo.

\begin{tabular}{llc}
\hline Visitante & \multicolumn{2}{c}{ Avistamentos } \\
& N & Porcentagem \\
\hline Ramphodon naevius Dumont & 90 & 38,30 \\
Glaucis hirsuta J.F. Gmelin & 86 & 36,60 \\
Thalurania glaucopis J.F. Gmelin & 34 & 14,47 \\
Aphantochroa cirrochloris Vieillot & 18 & 7,66 \\
Chlorostilbon aureoventris D'Orbigry \& Lafresnaye & 4 & 1,70 \\
Melanotrochilus fuscus Vieillot & 2 & 0,85 \\
Leucochloris albicollis Vieillot & 1 & 0,43 \\
TOTAL & 235 & 100,00 \\
\hline
\end{tabular}




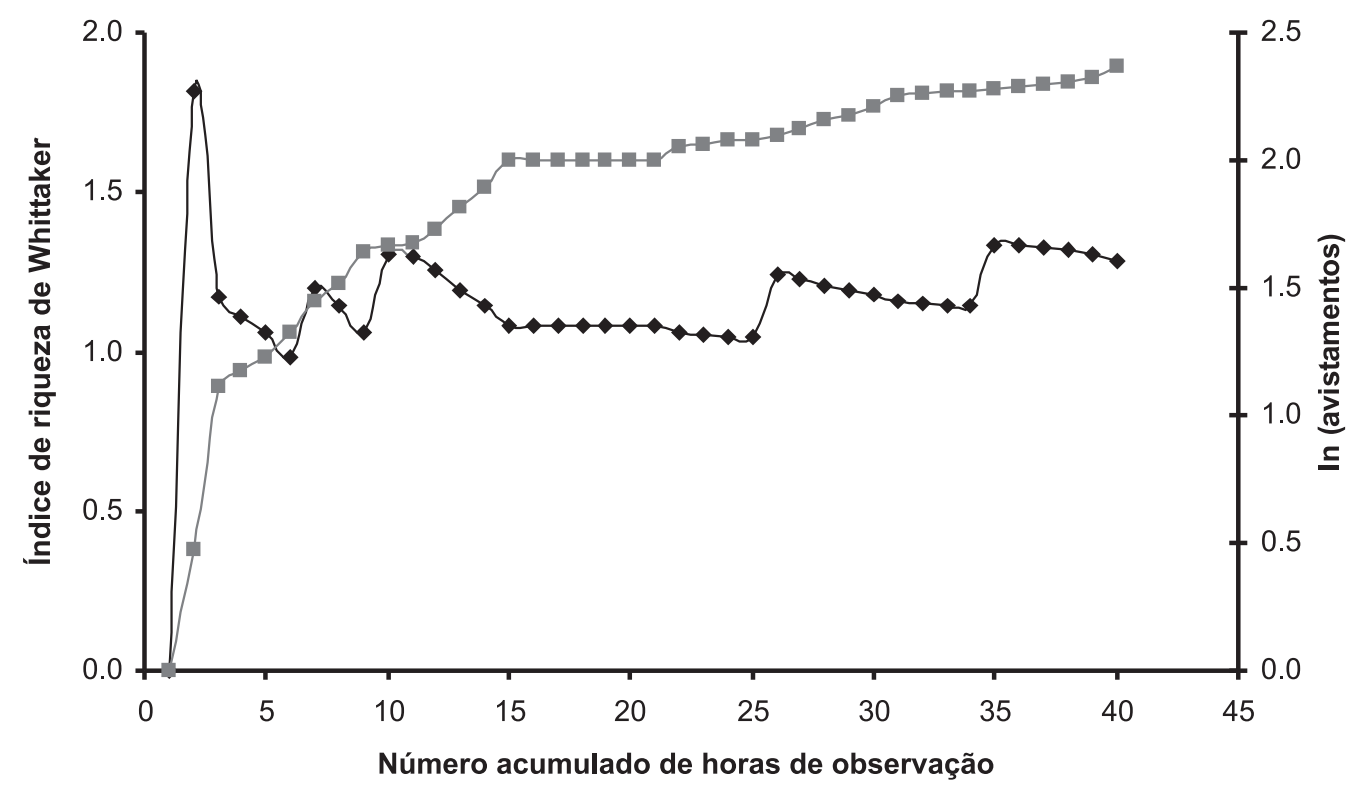

Figura 1 - Curva de esforço observacional para identificação da riqueza de espécies de beija-flores visitantes das espécies de bromélias em estudo: ( I Índice de Riqueza de Whittaker modificado ( $)$ logarítmo neperiano do número acumulado de avistamentos.

O maior índice de riqueza de espécies de visitantes florais foi de 1,82 , obtido após duas horas acumuladas de observação. Aumentando o número de horas de trabalho de campo, o índice de riqueza caiu para 1,31, sofrendo novas quedas até ser restabelecido com valores 1,24, após 15 horas, e 1,33 após 35 horas (Fig. 1).

\section{Morfologia floral}

Foram observados indivíduos epífitos e terrestres de quatro espécies de bromélias: Aechmea araneosa L.B.Sm., Aechmea chlorophylla L.B.Sm., Billbergia amoena (Lood.) Lindl. e Tillandsia geminiflora Brongn. Os dados morfológicos gerais das flores e das espécies estudadas são apresentados na tabela 2 .

\section{Visitantes florais}

As características morfométricas do corpo e bico das sete espécies de beija flores estudadas estão na tabela 3. Aphantochroa cirrochloris foi observado forrageando as espécies vegetais $A$. chlorophylla e $B$. amoena, com abordagem direta à flor, sem adejamentos de inspeção. Ao visitar B. amoena, a testa e o bico do beija-flor tocaram os verticilos reprodutivos, somente o bico desta espécie animal tocou os verticilos reprodutivos de $A$. chlorophylla.

Chlorostilbon aureoventris foi observado forrageando nas flores de $A$. araneosa e $T$. geminiflora, entrando, algumas vezes, em encontros agonísticos com outras espécies de beija-flores. Ao abordar a flor, notase um rápido adejamento antes do tomar néctar. Em ambas as espécies vegetais visitadas, somente o bico do beija-flor toca os verticilos reprodutivos.

Melanotrochilus fuscus foi observado forrageando a espécie vegetal $A$. araneosa, com abordagem direta à flor. Durante a visita, somente o bico desse beija-flor tocava os verticilos reprodutivos.

Glaucis hirsuta foi observado forrageando e inspecionando A. chlorophylla e $B$. amoena, com abordagem direta à flor. Ao visitar B. amoena, a testa e o bico do beijaflor tocaram os verticilos reprodutivos, ao visitar A. chlorophylla, somente o bico desta espécie tocou os verticilos reprodutivos.

Ramphodon naevius foi observado forrageando A. chlorophylla e B. amoena, 
apresentando parada de adejamento anterior à tomada de néctar. Em algumas situações observou-se que esta espécie obteve encontros agonísticos com outros beija-flores visitantes. Ao visitar B. amoena, a testa e o bico do beijaflor tocaram os verticilos, enquanto ao visitar A. chlorophylla, somente o bico desta espécie tocava nas anteras e estigmas.

Thalurania glaucopis foi observado forrageando e inspecionando A. chlorophylla, com abordagem direta à flor, entrando algumas vezes em encontros agonísticos com outras espécies de beija-flores. Durante a visita, somente o bico de beija-flor tocava os verticilos reprodutivos.

Leucochloris albicollis foi observado forrageando e inspecionando a espécie vegetal A. chlorophylla, notando-se, durante a visita, uma pausa anterior ao forrageio. Durante a visita, somente o bico do beija-flor tocava os verticilos da flor.

O comportamento dos beija-flores em forrageio e em visita, apresentaram particularidades, refletindo ou não nos padrões territorialistas de defesa de recursos (Tab. 4) .

\section{Correlação entre comprimento $e$} curvatura de flores e bico de beija-flores

$\mathrm{O}$ estudo morfométrico das flores evidenciou que todas as espécies estudadas apresentavam certo grau de curvatura. Para a análise de regressão logística, os resultados das medidas arco e corda das corolas das bromélias e dos bicos dos beija flores estão, respectivamente, nas tabelas 5 e 6 . Para os beijaflores, dos sete visitantes, apenas G. hirsuta teve uma curvatura expressiva para o bico, enquanto os demais ficaram muito próximos do limite para aceitação de uma estrutura reta (Tab. 6).

Quando foi testado o ajuste entre parâmetros de comprimento e índice de curvatura dos bicos dos beija-flores em relação aos das flores das bromélias (Tab. 7), nenhum dos modelos estimados pela regressão logística ordinal se mostrou com ângulo da reta estimada significativamente diferente de zero, conforme valores de máxima verossimilhança (G), a não ser quando o índice de curvatura dos bicos foi testado em função da corda da corola.

Neste caso, como o coeficiente relacionado à corda das flores tem valor negativo, isto significa que as flores de maior corda tendem a se ajustar aos bicos de menor curvatura, que é uma condição predominante entre os beija-flores observados.

Tanto $R$. naevius quanto G. hirsuta e A. cirrochloris visitaram flores de B. amoena e A. chlorophylla. Considerando-se a média da corda da corola de cada espécie e comparando com a média da corda dos bicos das espécies visitantes comuns a elas, não observamos uma associação entre eles (Tab. 7). Também considerando a média da curvatura (arco) e a média do índice de curvatura (IC) das flores, comparando com as mesmas medidas tiradas dos bicos das espécies visitantes envolvidas, essa informação se confirma (Tab. 7).

Thalurania glaucopis e L. albicollis foram observados forrageando $A$. chlorophylla. A comparação entre as médias de arco, corda e índice de curvatura dos bicos das duas espécies visitantes e as mesmas medidas tiradas das flores de A. chlorophylla também não apresentou associação significativa entre as medidas (Tab. 7).

Chlorostilbon aureoventris visitou T. geminiflora e ao comparar as médias de arco, corda e índice de curvatura da corola da flor com as médias de arco, corda e índice de curvatura do bico desse visitante, observa-se uma correlação considerável entre essas medidas. Porém, C. aureoventris também foi observado forrageando A. araneosa, visitada também por $M$. fuscus, que possui maiores médias de arco e corda do bico que as de C. aureoventris. Além disso, as médias de arco, corda e índice de curvatura das flores em A. araneosa não apresentam associação significativa com as médias dos bicos de nenhuma das duas espécies visitantes citadas. 
Tabela 2 - Características morfológicas gerais e visitantes das flores das espécies de bromélias estudadas e beija-flores visitantes na Estação Biológica de Santa Lúcia, Santa Teresa, Espírito Santo.

\begin{tabular}{|c|c|c|c|c|c|c|c|c|}
\hline \multirow[t]{2}{*}{ Espécie } & \multirow{2}{*}{$\begin{array}{c}\text { Cor } \\
\text { da } \\
\text { pétala }\end{array}$} & \multirow{2}{*}{$\begin{array}{l}\text { Horário } \\
\text { de } \\
\text { Abertura }\end{array}$} & \multirow{2}{*}{$\begin{array}{l}\text { Longevidade } \\
\text { (dias) }\end{array}$} & \multicolumn{2}{|c|}{ Corola } & \multirow{2}{*}{$\begin{array}{l}\text { Altura } \\
\text { Gineceu } \\
\quad(\mathbf{m m}) \\
\end{array}$} & \multirow[b]{2}{*}{$\begin{array}{c}\text { Androceu } \\
(\mathbf{m m})\end{array}$} & \multirow{2}{*}{ Visitantes } \\
\hline & & & & $\begin{array}{c}\text { Comprimento } \\
(\mathbf{m m})\end{array}$ & $\begin{array}{l}\text { Diâmetro } \\
(\mathbf{m m})\end{array}$ & & & \\
\hline A. araneosa & amarela & $5: 20 \mathrm{~h}$ & 5 & $\begin{array}{l}17,37 \\
( \pm 2,81)\end{array}$ & $\begin{array}{l}5,18 \\
( \pm 0,05)\end{array}$ & $\begin{array}{l}10,56 \\
( \pm 0,73)\end{array}$ & $\begin{array}{l}10,82 \\
( \pm 0,78)\end{array}$ & $\begin{array}{l}\text { M. fuscus, } \text { C. aureoventris } \\
\text { A. cirrochloris }\end{array}$ \\
\hline A. chlorophylla & amarela & $4: 30 \mathrm{~h}$ & 1 & $\begin{array}{l}27,66 \\
( \pm 3,44)\end{array}$ & $\begin{array}{l}9,72 \\
( \pm 0,07)\end{array}$ & $\begin{array}{l}19,95 \\
( \pm 1,17)\end{array}$ & $\begin{array}{l}22,11 \\
( \pm 0,31)\end{array}$ & $\begin{array}{l}\text { R. naevius, G. hirsuta, } \\
\text { A. cirrochloris, T. glaucopis, }\end{array}$ \\
\hline & & & & & & & & L. albicollis \\
\hline B. amoena & $\begin{array}{l}\text { esverdeada, com } \\
\text { máculas brancas e } \\
\text { violáceas nas } \\
\text { extremidades }\end{array}$ & $4: 30 \mathrm{~h}$ & 3 & $\begin{array}{l}42,55 \\
( \pm 3,41)\end{array}$ & $\begin{array}{l}7,96 \\
( \pm 0,11)\end{array}$ & $\begin{array}{l}39 \\
( \pm 16,30)\end{array}$ & $\begin{array}{l}48 \\
( \pm 2,34)\end{array}$ & $\begin{array}{l}\text { R. naevius, G. hirsuta, } \\
\text { T. glaucopis }\end{array}$ \\
\hline T. geminiflora & rosa & $5: 50 \mathrm{~h}$ & 6 & $\begin{array}{l}17,04 \\
( \pm 1,03)\end{array}$ & $\begin{array}{l}4,33 \\
( \pm 0,38)\end{array}$ & $\begin{array}{l}9,18 \\
( \pm 0,33)\end{array}$ & $\begin{array}{l}11,74 \\
( \pm 0,39)\end{array}$ & C. aureoventris \\
\hline
\end{tabular}

Tabela 3 - Características morfométricas dos beija-flores e das bromélias por eles utilizadas como fonte de néctar na Estação Biológica de Santa Lúcia, Santa Teresa, Espírito Santo.

\begin{tabular}{|c|c|c|c|c|}
\hline \multirow{2}{*}{$\begin{array}{l}\text { Beija-flor (N) } \\
\text { G. hirsuta }\end{array}$} & \multirow{2}{*}{$\begin{array}{c}\text { Comprimento Total (mm) } \\
120\end{array}$} & \multirow{2}{*}{$\begin{array}{l}\text { Comprimento do Bico (mm) } \\
26,40( \pm 4,47)\end{array}$} & \multicolumn{2}{|c|}{ Bromélias visitadas } \\
\hline & & & A.chlorophylla & B. amoena \\
\hline R. naevius & 119 & $31,39( \pm 0,72)$ & A. chlorophylla & B. amoena \\
\hline T. glaucopis & 110 & $19,37( \pm 1,21)$ & A. chlorophylla & \\
\hline L. albicollis & 100 & $21,53( \pm 0,95)$ & A. chlorophylla & \\
\hline A. cirrochloris & 120 & $22,19( \pm 0,09)$ & A. chlorophylla & B. amoena \\
\hline C. aureoventris & 85 & $17,51( \pm 2,68)$ & A. araneosa & T. geminiflora \\
\hline M. fuscus & 125 & $32,01( \pm 1,46)$ & A. araneosa & \\
\hline
\end{tabular}


Tabela 4 - Padrões comportamentais de visitação dos beija-flores às flores das bromélias estudadas na Estação Biológica de Santa Lúcia, Santa Teresa, Espírito Santo.

\begin{tabular}{llll}
\hline Visitante & Bromélia & Comportamento & Abordagem à flor \\
\hline G. hirsuta & A. chlorophylla & Forrageio e inspeção & Direta \\
G. hirsuta & B. amoena & Forrageio e inspeção & Direta \\
M. fuscus & A. araneosa & Forrageio & Direta \\
R. naevius & A. chlorophylla & Forrageio e defesa & Adejamento prévio \\
R. naevius & B. amoena & Forrageio e defesa & Adejamento prévio \\
C. aureoventris & A. araneosa & Forrageio e defesa & Adejamento prévio \\
C. aureoventris & T. geminiflora & Forrageio e defesa & Adejamento prévio \\
A. cirrochloris & A. chlorophylla & Forrageio & Direta \\
A. cirrochloris & B. amoena & Forrageio & Direta \\
T. glaucopis & A. chlorophylla & Forrageio, defesa e inspeção & Direta \\
L. albicollis & A. chlorophylla & Forrageio e inspeção & Adejamento prévio \\
\hline
\end{tabular}

Tabela 5 - Avaliação morfométrica das corolas das bromélias observadas na Estação Biológica de Santa Lúcia, Santa Teresa, Espírito Santo. IC=Índice de Curvatura.

\begin{tabular}{lllc}
\hline Bromélia & Corda $(\mathbf{m m})$ & Arco $(\mathbf{m m})$ & IC \\
\hline Aechmea araneosa $(\mathrm{n}=5)$ & $10,25( \pm 3,36)$ & $13,48( \pm 5,33)$ & $1,29( \pm 0,1)$ \\
Aechmea chlorophylla $(\mathrm{n}=5)$ & $20,92( \pm 5,95)$ & $26,28( \pm 5,52)$ & $1,28( \pm 0,09)$ \\
Billbergia amoena $(\mathrm{n}=5)$ & $39,22( \pm 3,66)$ & $45,73( \pm 5,18)$ & $1,16( \pm 0,08)$ \\
Tillandsia geminiflora $(\mathrm{n}=5)$ & $17,49( \pm 0,93)$ & $19,74( \pm 0,64)$ & $1,12( \pm 0,08)$ \\
\hline
\end{tabular}

Tabela 6 - Avaliação morfométrica dos bicos dos beija-flores observados na Estação Biológica de Santa Lúcia, Santa Teresa, Espírito Santo.

\begin{tabular}{lllc}
\hline Beija-Flor & Corda $(\mathbf{m m})$ & Arco $(\mathbf{m m})$ & IC \\
\hline Aphantochroa cirrochloris $(\mathrm{n}=2)$ & $22,19( \pm 0,09)$ & $23,50( \pm 1,49)$ & $1,05( \pm 0,06)$ \\
Chlorostilbon aureoventris $(\mathrm{n}=4)$ & $17,51( \pm 2,68)$ & $18,33( \pm 2,65)$ & $1,05( \pm 0,03)$ \\
Glaucis hirsuta $(\mathrm{n}=5)$ & $26,40( \pm 4,47)$ & $29,45( \pm 5,17)$ & $1,11( \pm 0,01)$ \\
Leucochloris albicollis $(\mathrm{n}=4)$ & $21,53( \pm 0,95)$ & $23,00( \pm 1,15)$ & $1,06( \pm 0,05)$ \\
Melanotrochilus fuscus $(\mathrm{n}=3)$ & $32,01( \pm 1,46)$ & $32,79( \pm 1,26)$ & $1,02( \pm 0,01)$ \\
Ramphodon naevius $(\mathrm{n}=2)$ & $31,39( \pm 0,72)$ & $33,17( \pm 0,72)$ & $1,06( \pm 0,00)$ \\
Thalurania glaucopis $(\mathrm{n}=7)$ & $19,37( \pm 1,21)$ & $20,88( \pm 1,56)$ & $1,07( \pm 0,04)$ \\
\hline
\end{tabular}


Tabela 7 - Regressão logística ordinal entre corda e índice de curvatura (IC) dos bicos de beijaflores e de flores de bromélias. Z: valor padronizado do coeficiente pela curva normal reduzida; $p$ : nível de significância, *: teste significativo; gl: graus de liberdade.

\begin{tabular}{|c|c|c|c|c|c|c|c|}
\hline \multirow[t]{2}{*}{ Modelos } & \multirow[t]{2}{*}{ Coeficiente } & \multirow[t]{2}{*}{$\begin{array}{c}\text { Erro } \\
\text { Padrão }\end{array}$} & \multirow[t]{2}{*}{$Z$} & \multirow[t]{2}{*}{$p$} & \multicolumn{3}{|c|}{$\begin{array}{c}\text { Taxa de risco e limites } \\
(95 \%)\end{array}$} \\
\hline & & & & & Taxa & Inferior & Superior \\
\hline \multicolumn{8}{|l|}{ Corda da flor em relação à } \\
\hline Corda do bico dos beija-flores & $-0,03$ & 0,05 & $-0,58$ & $0,57^{\mathrm{ns}}$ & 0.97 & 0,88 & 1,07 \\
\hline $\mathrm{G}=0.313, p=0.58, \mathrm{gl}=1$ & Pearson $\chi^{2}$ & $=15.84$ & $p=$ & 0.58 & $\mathrm{gl}=17$ & & \\
\hline \multicolumn{8}{|l|}{ Corda da flor em relação ao } \\
\hline IC do bico dos beija-flores & $-0,13$ & 0,06 & $-2,10$ & $0,04 *$ & 0,88 & 0,77 & 0,99 \\
\hline $\mathrm{G}=5,364, p=0.02, \mathrm{gl}=1$ & Pearson $\chi^{2}$ & $=6,61$ & $p=$ & 0.83 & $\mathrm{gl}=11$ & & \\
\hline \multicolumn{8}{|l|}{ IC da flor em relação à } \\
\hline Corda do bico dos beija-flores & $-4,67$ & 7,86 & $-0,59$ & $0,55^{\text {ns }}$ & 0,01 & 0,00 & 46257,0 \\
\hline $\mathrm{G}=0,319, p=0,57, \mathrm{gl}=1$ & Pearson $\chi^{2}$ & $=7,64$ & $p=$ & 0.75 & $\mathrm{gl}=7$ & & \\
\hline \multicolumn{8}{|l|}{ IC da flor em relação ao } \\
\hline IC do bico dos beija-flores & 3,79 & 8,08 & 0,47 & $0,64^{\text {ns }}$ & 44,06 & 0,00 & $3,32 \times 10^{8}$ \\
\hline $\mathrm{G}=0,210, p=0,65, \mathrm{gl}=1$ & Pearson $\chi^{2}$ & $=8,81$ & $p=$ & 0.27 & $\mathrm{gl}=7$ & & \\
\hline
\end{tabular}

\section{Discussão}

Durante o estudo de padrões fenológicos e polinização de comunidade de bromélias na EBSL, Varassin \& Sazima (2000) constataram que os beija-flores foram os polinizadores principais de $84 \%$ das espécies de bromélias, sendo que, além dos beija-flores, em $63 \%$ do total das bromélias, borboletas ou abelhas também foram polinizadores. A análise de agrupamento das plantas visitadas pelos polinizadores evidenciou que houve semelhança no conjunto de plantas visitadas pelos beijaflores, sendo que os beija-flores de bico longo, como $R$. naevius, por exemplo, visitaram um conjunto de bromélias distinto das espécies utilizadas por beija-flores de bico curto, como T. glaucopis.

Varassin \& Sazima (2000), num trabalho realizado em 1 ha amostrado na EBSL entre 1997 e 1998, perfazendo cerca de 960 horas de trabalho de campo, registraram nove espécies de beija-flores. Neste trabalho, realizado numa localidade diferente da mesma Reserva, em 40 horas de observação de visitantes florais, foram avistadas sete espécies de beija-flores, cinco das quais foram comuns às nove encontradas pelas referidas autoras. Como o índice de riqueza de espécies de beijaflores aqui encontrado não apresentava mais variações expressivas enquanto a curva logarítmica de avistamentos acumulado tendia a uma assíntota, há fortes evidências de que o conjunto de espécies observadas são satisfatoriamente representativas da riqueza local.

Fischer (1994) observou que flores de corola longa (maior que $3 \mathrm{~cm}$ ) apresentam em geral néctar mais concentrado do que as flores de corola curta (menor do que $3 \mathrm{~cm}$ ). Segundo o referido autor, este fato poderia estar relacionado a uma especialização entre bromeliáceas de corola longa e beija-flores de bico longo, visto que, beija-flores de bico curto aparentemente não alcançam o néctar das flores de corola longa. Entre as bromélias da EBSL, houve um grupo de espécies polinizadas por beija-flores de bico longo e outro polinizado por beija-flores de bico curto, além de um grupo 
polinizado por borboletas (Varassin \& Sazima 2000). Esta associação, porém, não seria espécie específica (Snow \& Teixeira 1982), mas poderia possivelmente ter seguido um modelo de coevolução difusa, durante a qual tipos gerais, como beija-flores de bico longo, tenham influenciado a evolução de alguns grupos de plantas (Sazima et al. 1996) tais como as bromélias.

No entanto, Sakai et al. (1998) constataram, analisando a relação estrutural flor-polinizador, que a morfologia floral de algumas das espécies vegetais observadas não se ajustava perfeitamente às características de seus polinizadores. Então, sugeriram que a visita do polinizador pode variar, em parte, dependendo da quantidade disponível de néctar. Já a quantidade de néctar, por sua vez, pode mudar de acordo com a frequiência de visitas recebidas, ou densidade de polinizadores, já que a disponibilidade de néctar deve mudar se o número de visitas diminuir. Nesse caso, os visitantes podem procurar outras espécies vegetais para se alimentar.

A morfologia floral é um dos mais importantes aspectos de interações plantapolinizador, pois determina a acessibilidade do polinizador ao néctar, eficiência da deposição do pólen no corpo do polinizador, e eficiência de aquisição do pólen pelo estigma através dos vetores (Sakai et al. 1998). Dentro do conceito de síndrome de polinização, espera-se que as características florais sejam correlacionadas com a dos polinizadores, de tal maneira que, nas espécies de planta que se especializaram num determinado tipo de polinizador, elas se converteriam num conjunto de características fenotípicas que as adaptam à morfologia, fisiologia sensorial e nutricional, e ao comportamento desse polinizador. No entanto, ecologistas da área discordam desse conceito, por observarem que muitas flores complexas recebem visitas de diversos tipos de animais (Waser et al. 1996). Isto permite considerar que, como foi observado neste trabalho, as medidas florais não necessariamente tenham que ter correlação com as medidas dos visitantes.
Estas idéias de ajustes morfológicos recíprocos entre flores e polinizadores proliferaram como hipóteses a serem testadas. O modelo aqui estudado se revelou útil ao teste de hipóteses desta natureza. A análise de regressão logística apresentou-se como metodologia de fácil aplicação a um conjunto de dados satisfatoriamente amostrados.

Embora as quatro espécies de bromélias estudadas representem uma parcela muito pequena da diversidade total de espécies desta família, de modo que um conjunto amostral maior precisa ser estudado, incluindo outros grupos taxonômicos vegetais. Destacamos que, para produzir evidências mais consistentes, torna-se necessário ir além das puras constatações visuais e, apesar de simples, o teste de hipótese da forma em que foi aqui aplicado pode contribuir para isto.

\section{Agradecimentos}

Ao Museu de Biologia Professor Mello Leitão pelo acesso às coleções zoológicas e bibliográficas e pela autorização e apoio logístico para realização dos trabalhos de campo na Reserva Santa Lúcia. A Antônio Carlos Dalcolmo e Jorge Antônio Capucho pelo incentivo e acompanhamento nos trabalhos de campo. A Glória Matallana Tobón (UFRJ) pela orientação na etapa inicial do projeto e a Thiago dos Santos Coser pela identificação das espécies de bromélias. A Roseana Brumana do Nascimento e Glória M. Tobón, pelas sugestões e correções em uma versão prévia e a um revisor anônimo cujas sugestões foram fundamentais para uma melhor compreensão do texto.

\section{REFERÊNCIAS BIBLIOGRÁFICAS}

Bawa, K. S.; Bullock, S. H.; Perry, D. R.; Coville, R. E. \& Grayum, M. H. 1985. Reproductive biology of tropical lowland rain forest trees: II. pollination systems. American Journal of Botany 72: 346-356.

Faegri, K. \& van der Pijl, L. 1979. Principles of pollination ecology. $3^{\text {rd }}$ ed. Pergamon Press, Oxford, 214p. 
Feinsinger, P. 1983. Coevolution and pollination. In: Futuyama, D. J. \& Slatkin, M. (eds.). Coevolution. Sinauer Associates Inc., Sunderland. Pp. 282-310.

Fenster, C. B.; Armbruster, W. S.; Wilson, P.; Dudash, M. R. \& Thomson, J. D. 2004. Pollination syndromes and floral specialization. Annual Review of Ecology, Evolution and Systematics 35: 375-403.

Fischer, E. A. 1994. Polinização, fenologia e distribuição espacial de Bromeliaceae numa comunidade de Mata Atlântica, litoral sul de São Paulo. Dissertação de Mestrado. Universidade Estadual de Campinas, Campinas, 80p.

Herrera, C. M. 1996. Floral traits and plant adaptation to insect pollinators: a devil's advocate approach. In: Lloyd, D. C. \& Barrett, S. C. H. (eds). Floral Biology, studies on floral evolution in animal pollinated plants. Chapman \& Hall, New York. Pp. 65-87.

Hosmer, D. W. \& Lemeshow, S. 1989. Applied logistic regression. John Wiley, New York, 305p.

Krebs, C. J. 1999. Ecological methodology. $2^{\text {nd }}$ ed. Benjamin Cummings, Menlo Park, 620p.

Proctor, M.; Yeo, P. \& Lack, A. 1996. The study of pollination: a short history. In: Proctor, M.; Yeo, P. \& Lack, A. The natural history of pollination. Harper Collins, London. Pp. 12-23.

Roubik, D. M. 1992. Loose niches in tropical communities: why are there so few bees and so many trees? In: Hunter, M. D.; Ohgushi, T. \& Price, P. W. (ed.). Effects of resource distribution on animal-plant interactions. Academic Press, San Diego. Pp. 327-354.

Sakai, S.; Kato, M. \& Inoue, T. 1998. Three pollination guilds and variation in floral characteristics of Bornean gingers (Zingiberaceae and Costaceae). American Journal of Botany 86: 646-658.

Sazima, I.; Buzato, S. \& Sazima, M. 1996. An assemblage of hummingbird-pollinated flowers in a montane forest in southeastern Brazil. Botanica Acta 83: 705-712.

Snow, D. W. \& Teixeira, D. L. 1982. Hummingbirds and their flowers in the costal mountains of southeastern Brazil. Journal of Ornithology 123: 446-450.

Varassin, I. G. \& Sazima, M. 2000. Recursos de Bromeliaceae utilizados por beija-flores e borboletas em Mata Atlântica no sudestes do Brasil. Boletim do Museu de Biologia Mello Leitão 11/12: 57-70.

Waser, N. M. 1983. The adaptative nature of floral traits: ideas and evidence. In: Real, L. (ed.). Pollination biology. Academic Press, Orlando. Pp. 242-285.

; Chittka, L.; Price M. V.; Williams N. M. \& Ollerton, J. 1996. Generalization in pollination systems, and why it matters. Ecology 77: 1043-1060.

Whittaker, R. H. 1975. Comunities and ecosystems. $2^{\text {nd }}$ ed. Macillan, New York, 385p. 